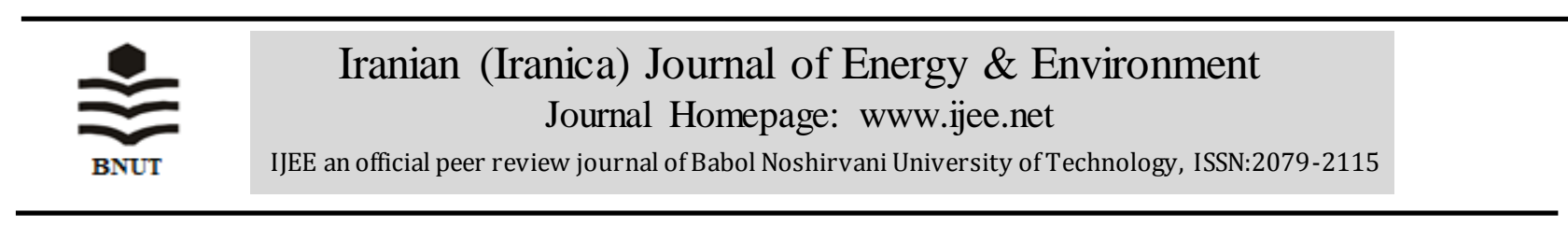

\title{
Effect on Autogenous Healing in Concrete by Fly Ash and Rice Husk Ash
}

\author{
V. Kanthe*, S. Deo, M. Murmu \\ Department of Civil Engineering, NIT Raipur, Chhattisgarh, India
}

\section{P A P ER I NFO}

\section{Paperhistory:}

Received 01 April 2019

Accepted in revised form 24 June 2019

\section{Keywords:}

Autogenous Healing

Concrete

Fly Ash

Rice Husk Ash

\section{A $B S T T R A C T$}

In this research paper, the effect on autogenous healing in concrete by cementitious material such as fly ash (FA) and rice husk ash (RHA) are reported. The utilization of waste byproduct are the interest in research for healing of concrete. The non-destructive testing and microstructure analysis were conducted to quantify autogenous healing in concrete. The concrete specimens prepared with different proportion of FA and RHA. The satisfactory results of non- destructive test were obtained with respect to the durability of concrete. In the chemical and microstructure analysis the calcium carbonate crystals formed on healed cracks surface and dense particle packing in the matrix of concrete were observed. This type of ternary blend is useful for making durable and sustainable concrete structure. The utilization of industrial and agricultural byproduct reduces the effect of environmental pollution and also reduces the consumption of cement with the same reduction in $\mathrm{CO}_{2}$ emition from cement industry.

doi: $10.5829 /$ ijee.2019.10.02.13

\section{INTRODUCTION}

The concrete structures are ordinarily cracked. Cracks may happen because of numerous reasons, for instance, mechanical stacking or limited shrinkage. Cracks have many negative consequences for the mechanical execution and durability of concrete structures. Despite the fact that breaking is normally not an issue of quick wellbeing, the strength of a strengthened concrete structure might be endangered if wide cracks are available in the concrete cover. It has been for quite some time realized that concrete cracks have a specific capacity to mend under great conditions. This component is called autogenous (self) healing, now and again alluded to as self-shutting, when no critical recuperation in mechanical qualities is accomplished. Autogenous healing was first seen to happen in water holding structures and pipes. The outline of various reasons for autogenous healing was appeared in Figure 1, in which a material has as of now the capacity to healing itself. There are numerous techniques for self-healing of concrete improvement, for example, utilizing microbes [1], crystalline admixture and using different chemical and cementitious mineral admixtures. The cementitious material has also the capability of healing the cracks in concrete [2]. The cementitious material such as fly ash and slag were used for the healing cracks in concrete. The cementitious materials were used in concrete for igh performance and increasing the mechanical and durability properties of the concrete. The ternary blend concrete was preferred for making sustainable high strength concrete and durable concrete using cementitious material [3-5]. Many of the waste byproduct producec from industries such as ground granulated blastfurnace slag (GGBS), slag, slurry, fly ash etc.[6-8]. The high strength concrete was reached by using low down watercement ratio. The low down water-cement ratio was chances for developing micro cracks and these cracks may lead to corrosion and reduced strength. Hence, the self-healing of cracks was in interest. The major aim of this research is to study the outcome of FA and RHA mineral admixture on autogenous healing performance of ternary blend concrete.

\section{Chemical process of autogenous healing in concrete}

The autogenous healing is occurring in the three possible chemical processes. The first is the hydration of unhydrated cement particles. The hydration of unhydrated cement may be a significant inclusion when crack widths are under 0.1 $\mathrm{mm}$ and cement is fresh. The second is the development of calcium carbonate and the development of precious stones on the crack appearances. The calcium particles beginning from the concrete pore arrangement respond with carbonate particles in the water and frame $\mathrm{CaCO}_{3}$, which accelerates in the crack. The third process occurs in seawater in the presence of $\mathrm{Mg}(\mathrm{SO})_{4}$ in seawater due to this ettringite and brucite form in the crack [9]. 


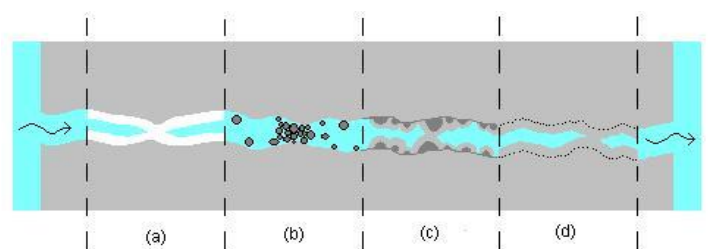

Figure 1. (a) Calcium carbonate or calcium hydroxide formation, (b) particles sedimentation, (c) continued hydration, (d) swelling of the cement matrix [1, 10]

\section{MATERIAL AND METHODS}

\section{Material}

In this research work the nearby existing materials were used it include ordinary portland cement (OPC), river sand, coarse aggregate, water, FA and RHA. The OPC 43 grade with specific gravity 3.13 was used in all composition of concrete mix conforming to IS: 4031 (1988) [11]. The nearby existing river sand with specific gravity 2.61 and Zone II was used as a fine aggregate. The $20 \mathrm{~mm}$ maximum size of coarse aggregate was used with specific gravity 2.64 conforming to IS: 383(1970). The FA was arranged from a power plant situated at Bhilai, Chhattisgarh, India. The processed RHA was arranged from the nearby merchant, the rice husk ash was collected from boiled rice mill and it reburned in the furnace at controlled temperature, after the burning the ash was cooled and ground it in powder form. The details of the physical and chemical properties of FA and RHA are summarized in Table 1. To examine the effects of autogenous healing of concrete the process was used in this research consists of four stages first, to create controlled crack in the specimens, second, to calculate of the revival of certain properties, such as ultrasonic pulse velocity (UPV) test and ER, third, the environmental contact needed to attain better healing results and, finally, the assessment of the revival of the same property determined in the second stage.

\section{Concrete mix}

The mix proportion of concrete was done as per the IS: 10262- 2009 [12]. The details of the concrete mix proportion are summarized in Table 2 . The concrete cube moulds of size $100 \times 100 \times 100 \mathrm{~mm}$ were used for concrete casting for all concrete mix. The concrete cubes were demoulded after 24 hours and placed for curing in the water tank for the period of 28 days.

TABLE 1. Physical and Chemical Properties of FA, RHA, and OPC

\begin{tabular}{lccc}
\hline \multirow{2}{*}{ Chemicals } & \multicolumn{3}{c}{ Elemental Contents $(\%)$} \\
\cline { 2 - 4 } Silica $(\mathrm{Si})$ & FA & RHA & OPC \\
Calcium (Ca) & 1.12 & 1.94 & 68.51 \\
Aluminum (Al) & 24.44 & 0.80 & 4.65 \\
Iron (Fe) & 5.01 & 1.12 & 3.76 \\
Magnesium (Mg) & 0.48 & 0.37 & 1.66 \\
Potassium (K) & 2.46 & 3.25 & 1.35 \\
Sodium (Na) & 0.11 & 0.07 & 0.37 \\
\hline Physical Properties & & & \\
\hline Specific Gravity & 2.22 & 2.45 & 3.13 \\
\hline
\end{tabular}

TABLE 2. Concrete Mix Proportion

\begin{tabular}{lccccccc}
\hline $\begin{array}{l}\text { Concrete } \\
\text { Mix }\end{array}$ & OPC & RHA & FA & $\begin{array}{c}\text { Coarse } \\
\text { Agg. }\end{array}$ & Sand & Water & $\begin{array}{c}\text { SP } \\
(\mathbf{0 . 5 \% )}\end{array}$ \\
\hline 100C0R0F & 450 & 0 & 0 & 1225 & 636 & 147 & 4.1 \\
80C10R10F & 360 & 45 & 45 & 1225 & 636 & 147 & 4.1 \\
70C10R20F & 306 & 45 & 90 & 1225 & 636 & 147 & 4.1 \\
60C10R30F & 270 & 45 & 135 & 1225 & 636 & 147 & 4.1 \\
\hline
\end{tabular}

\section{Pre-cracking of spacimen}

The specimens taken were for forming pre-cracked process after 28 days of curing period. The specimens were placed in compression testing machine and applied loading up to first visible crack. The widths of cracks were measured by using the crack scope. The details of the observed crack width were shown in Table 3.

\section{Environmental exposure conduction for healing}

After specified curing period and pre-cracking, the specimens were submerged in the water tank for the healing of cracks. The healed specimens were observed after 7 days then it was taken out from the water tank.

\section{Ultrasonic pulse velocity}

The UPV test was used to determine the quality of concrete such as consistency, rate or absence of internal flaws, cracks, and segregation by using the IS:13311 (part I): 1992 [13] guidelines, which have been used for analyzing the excellence of concrete in structures in terms of the UPV. The UPV value above the $4.5 \mathrm{~km} / \mathrm{s}$ considers as the excellent quality of concrete $[13,14]$. The UPV test was performed on the concrete specimen of all composition mix cured for 28 days before and after healing of cracks.

\section{Eectrical resistivity test}

The bulk electrical resistivity test was performed after the desired curing period before and after crack healing. The soaked wet concrete sample were set in the middle of two parallel conductive plates with the sodden wipe and ER meter. The voltage between two surfaces of the sample was determined by applying little exchanging current at the planned recurrence. The ER of before and after cracked healing concrete were determined by using the following Equation (1) $[15,16]$.

$\rho=\frac{A}{L} * Z$

where, ( $\rho)$ denotes the resistivity $(\Omega \mathrm{cm}),(\mathrm{A})$ denotes the sectional area of the specimen $\left(\mathrm{cm}^{2}\right)$, (L) denotes the specimen length $(\mathrm{cm})$ and $(\mathrm{Z})$ denotes the impedance measured by the device $(\Omega)$.

TABLE 3. Crack Width of Concrete Specimens

\begin{tabular}{lcc}
\hline Sr. No. & Concrete Mix & Crack Width $(\mathbf{m m})$ \\
\hline 1 & $100 \mathrm{C} 0 \mathrm{R} 0 \mathrm{~F}$ & $0.2 \mathrm{~mm}$ \\
2 & $80 \mathrm{C} 10 \mathrm{R} 10 \mathrm{~F}$ & $0.05 \mathrm{~mm}$ \\
3 & $70 \mathrm{C} 10 \mathrm{R} 20 \mathrm{~F}$ & $0.1 \mathrm{~mm}$ \\
4 & $60 \mathrm{C} 10 \mathrm{R} 30 \mathrm{~F}$ & $0.15 \mathrm{~mm}$ \\
\hline
\end{tabular}




\section{Partical packing theory}

The particle packing of concrete was tested by a Scanning Electron Microscope (SEM) machine from NIT Raipur. The sample prepared for SEM of size $1 \mathrm{~cm}$ cube with the polished surface. Then the samples were coated with Gold for a clear image. After that, the specimen was tested with highresolution magnification. The SEM image helps to understand the microstructure of concrete matrix.

\section{X-ray differaction test}

The X-Ray Diffraction (XRD) test was conducted to study the morphology of material used in this research work. The FA and RHA fine powder were used for XRD test. The powders were placed in XRD machine and test for $2 \theta$ degree angle.

\section{Energy dispersive X-ray spectroscopy}

The EDX test was used for study the chemical elemental contents of material sample collected from forming on the cracked surface of the concrete. The Gold plated samples were placed in the EDX machine with high-resolution magnification and high voltage charged.

\section{RESULT AND DISCUSSION}

\section{Autogenous healing of concrete}

After the 7 day curing period the cubes were taken out for observation of crack healing. The specimens before and after healed were shown in Figure 2 (a) to (d). The healing of
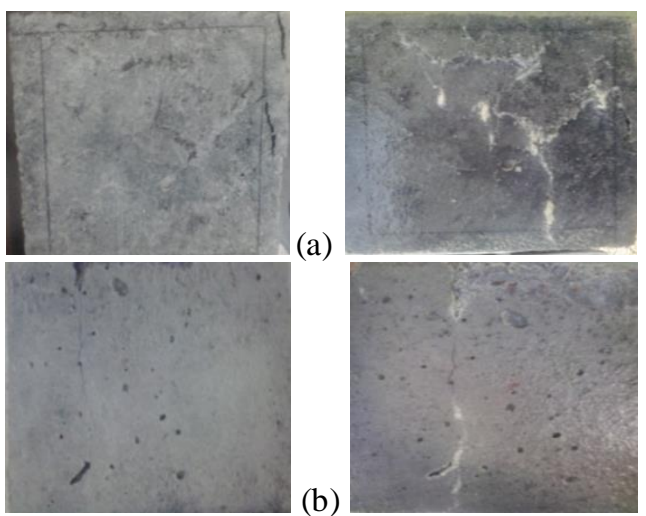

(b)
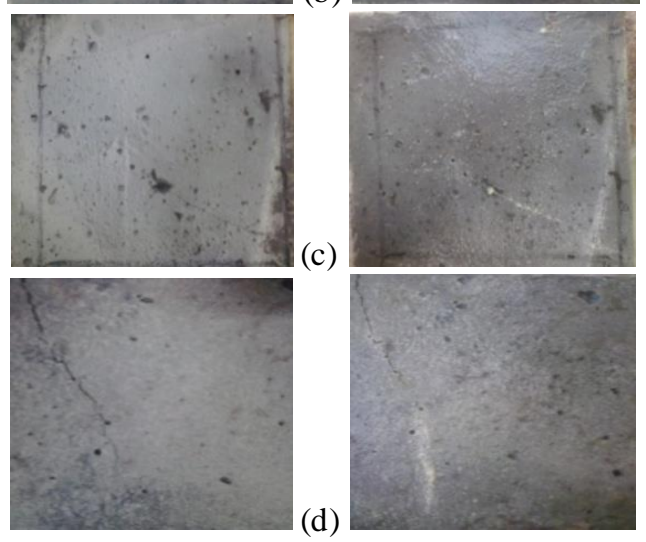

Figure 2. (a) Control concrete before and after autogenous healing, (b) before and after autogenous healing of R10F10 concrete mix, (c) before and after autogenous healing of R10F20 concrete mix, (d). before and after autogenous healing of r10f30 concrete mix concrete was observed in controlled concrete maximum calcium carbonate content on the crack surface other than the ternary mix. It was because of the ternary blend concrete made with FA and RHA. The silica content in FA and RHA react with a maximum content of unhydrated cement content (calcium hydroxide) than control concrete to form C-S-H gel (hydration process). The observed calcium carbonate on the cracked healed surface was shown a minimum in ternary blended concrete cracks and maximum on control concrete cracks. It was due to dense structure less moist was available for self healing. Hence, it was evident that the FA and RHA ternary blend concrete achieved more packing of particle and maximum utilization of unhydrated cement content in concrete to form secondary C-S-H gel. It will help for water seepage in the concrete structure and concrete make sustainable.

\section{Ultrasonic pulse velocity test}

he UPV test results for all ternary blended concrete mix before as well as after crack healing were greater than the control concrete. The details of the result were shown in Figure 3. This is possible due to better particle packing and the pozzolanic reaction of cementitious material. The UPV values showed higher than the control concrete for both mixes before and after crack healing. It was because of an increase in FA content, and mainly due to the autogenous crack healing.

\section{Eectrical resistivity}

The ER test was conducted with resistivity meter as instructed by ASTM C 1202 [17]. The records were produced for all ternary blend concrete mix before and after crack healing at 28 days. Figure 4 illustrate the raise in ER by rise the content of FA and RHA in concrete mixes for before and after crack healing than reference concrete mix. It was because of autogenous crack healing. It has occurred because of rise in the content of FA and RHA rect with the

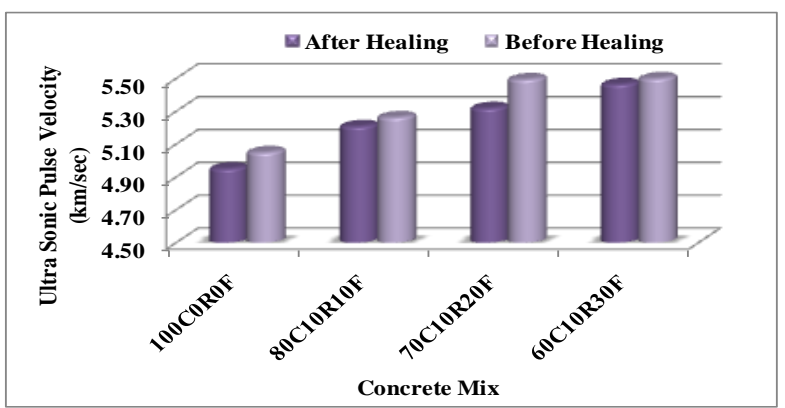

Figure 3. UPV for before and after cracked healing concrete

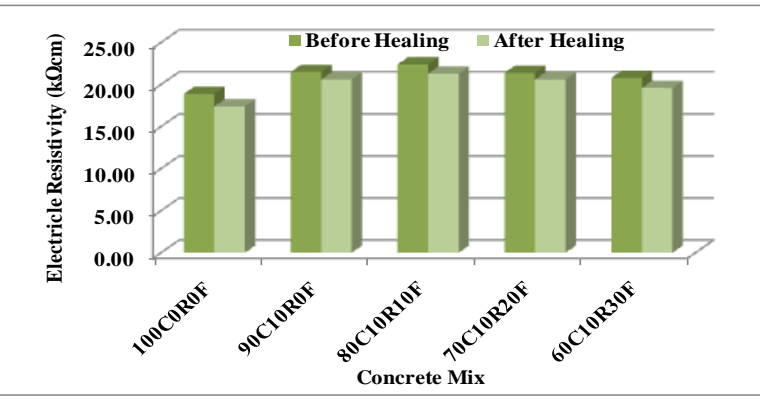

Figure 4. ER for before and after cracked healing concrete 
calcium hydroxide to generate secondary $\mathrm{C}-\mathrm{S}-\mathrm{H}$ gel. The relation between the rate of corrosion and ER are given in ACI Committee 222 [18]. It clearly showed the rise in the content of FA and RHA and due to autogenous crack healing lead to a lower rate of corrosion. The test results were established in a low to moderate range of corrosion with respect to ACI committee 222.

\section{Partical packing}

The particle packing of the concrete matrix was shown in Figure 5 for the SEM image. The dense CSH gel and fewer voids are shown in FA and RHA blended concrete than control concrete the similar result was found in a previous study [19]. It was because of the high reactivity of RHA and finer particle size of FA and RHA.

\section{XRD analysis}

Figure 6 (a) and (b) illustrates the morphology of FA and RHA sample. It was clear that the amorphous silica content present in RHA and FA. The amorphous silica content was responsible for forming the dense $\mathrm{CSH}$ gel.

\section{EDX analysis}

The EDX result was shown in Figure 7. It was clearly shown that the maximum elemental content of calcium presents in

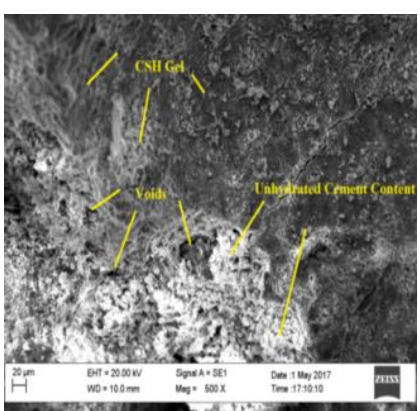

(a)

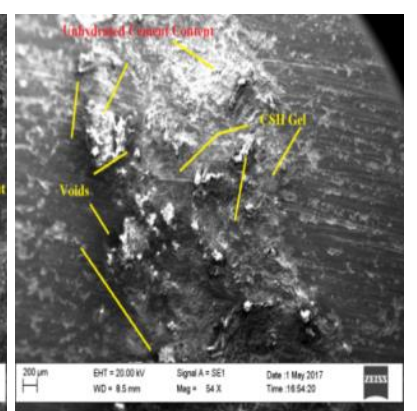

(b)
Figure 5. (a) Particle packing of control concrete, (b) particle packing of concrete made by RHA and FA.

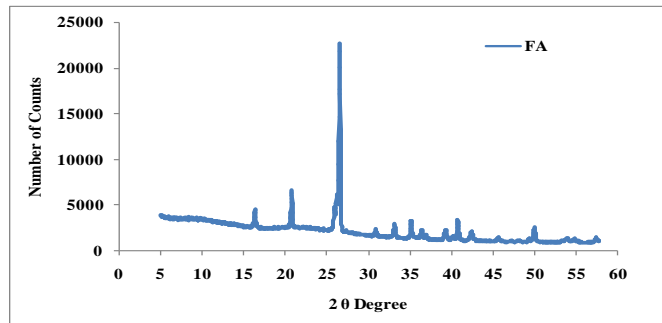

(a)

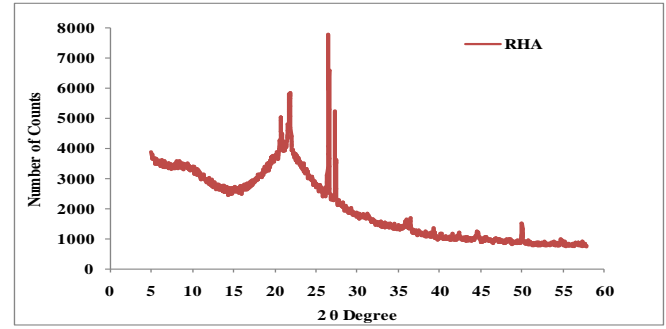

(b)

Figure 6. (a) XRD for FA, (b) XRD for RHA

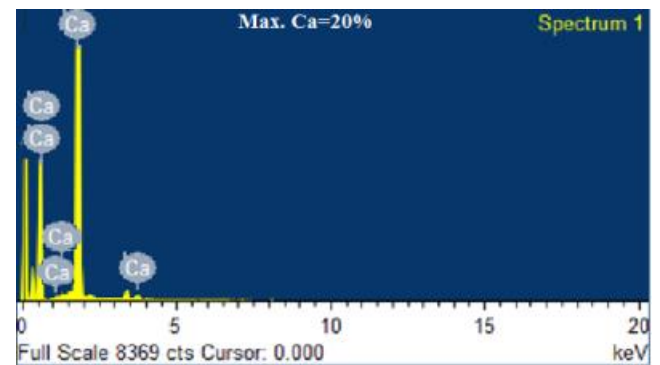

Figure 7. EDX analys is of the Healed sample

collected material from the healing of cracks the same result was also established by other researchers [20]. The amount of $\mathrm{Ca}$ was found to be $20 \%$. It was evident of the forming autogenous healing in crack was because of calcium carbonate forming in the cracks.

\section{CONCLUSIONS}

The following are the conclusions were drawn from the experimental result,

1. Lesser the autogenous healing was observed in the ternary blend than the control control because of the utilization of maximum content of unhydrated cement. It was proved by EDX result.

2. The ultrasonic pulse velocity after autogenous healing of concrete was almost similar to the before without cracked because of complete crack healing in concrete matrix and dense particle packing.

3. The electrical resistivity for after autogenous healing concrete was almost similar to the before cracked it was because of complete crack healing in concrete matrix, dense particle packing, and dens C-S-H gel forming in the concrete matrix.

4. The dense particle packing with fewer voids and dense $\mathrm{CSH}$ gel formed clearly shown in the microstructure of concrete.

5. The amorphous silica content was present in FA and RHA as found by XRD test to form CSH gel.

\section{ACKNOWLEDGEMENT}

The author would like to acknowledge to Director, HOD and Technical Education Quality Improvement Program (TEQIP-III), NIT Raipur, for financial support in the form of purchasing the required material. The author acknowledges to Department of Metallurgy, NIT Raipur for help in testing work through Scanning Electron Microscope (SEM) and XRay Diffraction (XRD).

\section{CONFLICT OF INTEREST}

There is no conflict of interest in this research work.

\section{REFERENCE}

1. K. Vijay, M. Murmu, and S. V Deo, "Bacteria based 
self healing concrete - A review," Construction and Building Materials., vol. 152, pp. 1008-1014, 2017.

2. N. D. B. D. Snoeck, "Repeated Autogenous Healing in Strain-Hardening Cementitious Composites by Using Superabsorbent Polymers," Journal of Materials in Civil Engineering, vol. 28, no. 1, pp. 1-11, 2016.

3. V. N. Kanthe, S. V Deo, and M. Murmu, "Use of Mineral Admixture in Concrete for Sustainable Development", International Journal of Innovative Research in Science, Engineer, vol. 3, no. 3, pp. 279284, 2017.

4. G. Shafabakhsh and S. Ahmadi, "Evaluation of Coal Waste Ash and Rice Husk Ash on Properties of Pervious Concrete Pavement," International Journal of Engineering-Transactions B: Applications, vol. 29, no. 2, pp. 192-201, 2016.

5. V. Sai Giridhar Reddy and V. Ranga Rao, "Eco-friendly Blocks by Blended Materials," International Journal of Engineering-Transactions B: Applications, vol. 30, no. 5, pp. 636-642, 2017.

6. S. Sharma, T. Gupta, and R. K. Sharma, "Assessment of Mechanical Properties of Concrete Containing Granite Slurry Waste", International Journal of EngineeringTransactions B: Applications, vol. 29, no. 5, pp. 599605, 2016.

7. Sharma, S. Kant Ransinchung, G D R NKumar and A. P.Roy,Kumar, "Comparison of Permeability and Drying Shrinkage of Self Compacting Concrete Admixed with Wollastonite Micro Fiber and Fly Ash", International Journal of Engineering-Transactions B: Applications, vol. 30, no. 11, pp. 1681-1690, 2017.

8. J. Y. Y. D. B. Zhang, Y. Zhang, T. Cheng, "New Analytic Method for Subgrade Settlement Calculation of the New Cement Fly ash Grave Pile slab Structure", International Journal of Engineering-Transactions A: Basics, vol. 29, no. 10, pp. 1364-1371, 2016.

9. B. Savija and E. Schlangen, "Autogeneous healing and chloride ingress in cracked concrete," Heron, vol. 61, no. 1, pp. 15-32, 2016.

10. H.E.J.G. Schlangen, H.M. Jonkers, S. Qian, and A. Garcia, "Recent advances on self healing of concrete",
In Fracture Mechanics of Concrete and Concrete Structures- Recent Advances in Fracture Mechanics of Concrete, 2010, no. 1, pp. 291-298.

11. Bureau of Indian Standard, "Indian Standard Method of Physical Test for Hydraulic Cement," IS 4031( Part 10), pp. 1-9, 1988.

12. Bureau of Indian Standard, "Concrete Mix Proportioning- Guidelines,” IS:12062, pp. 1-21, 2009.

13. Bureau of Indian Standard, "Non-Destructive Testing of Concrete Methods of Test," IS 13311 (PART 1), pp. 114, 1992.

14. C. S. C. Sreenivasulu, J. Guru Jawahar, "Predicting compressive strength of geopolymer concrete using NDT techniques", Asian Journal of Civil Engineering, vol. 19, no. 4, pp. 513-525, 2018.

15. V. N. Kanthe, S. V Deo, and M. Murmu, "Effect of fly ash and rice husk ash on strength and durability of binary and ternary blend cement mortar," Asian Journal of Civil Engineering, vol. 19, no. 8, pp.963-970, 2018.

16. B. Rath, S. Deo, and G. Ramtekkar, "Durable Glass Fiber Reinforced Concrete with Supplimentary Cementitious Materials", International Journal of Engineering-Transactions A: Basics, vol. 30, no. 7, pp. 964-971, 2017.

17. ASTM C1202, "Standard Test Method for Electrical Indication of Concrete's Ability to Resist Chloride Ion Penetration", American Society for Testing and Material (ASTM), pp. 1-8, 2012.

18. ASTM CI 222R-0, "Protection of Metals in Concrete Against Corrosion," American Society for Testing and Material (ASTM), pp. 1-41.

19. V. Kanthe, S. Deo, and M. Murmu, "Combine Use of Fly Ash and Rice Husk Ash in Concrete to Improve its Properties", International Journal of EngineeringTransactions A: Basics, vol. 31, no. 7, pp. 1012-1019, 2018.

20. M. D. Yang, Yingzi Lepech and V. C. Yang, En-hua Li, "Cement and Concrete Research Autogenous healing of engineered cementitious composites under wet - dry cycles", Cement and Concrete Research., vol. 39, no. 5, pp. 382-390, 2009.

\footnotetext{
DOI: 10.5829/ijee.2019.10.02.13

Persian Abstract

\begin{tabular}{|c|}
\hline 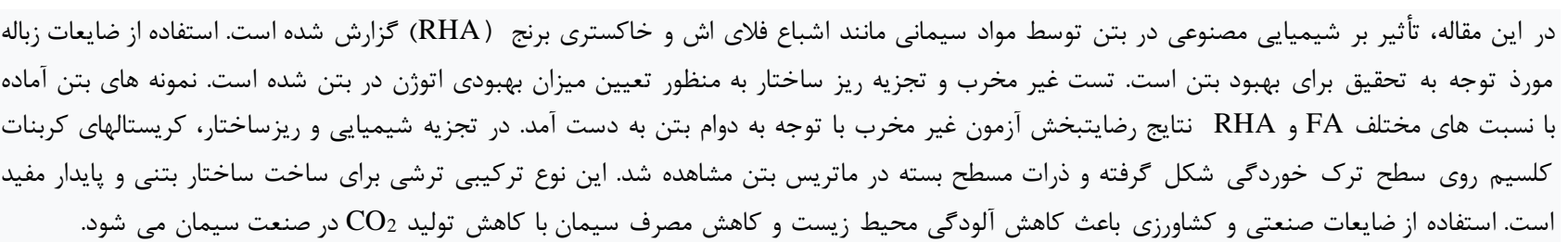 \\
\hline
\end{tabular}
}

